Original Paper

\title{
A Novel Approach to Estimate ROS Origination by Hyperbaric Oxygen Exposure, Targeted Probes and Specific Inhibitors
}

\author{
Quan Zhou Guoyang Huang Xuhua Yu Weigang Xu \\ Department of Diving and Hyperbaric Medicine, Naval Medical University, Shanghai, P. R. China
}

\section{Key Words}

Reactive oxygen species - Superoxide anion - Mitochondria respiratory chain $-\mathrm{NADPH}$ oxidase - Xanthine oxidase

\begin{abstract}
Background/Aims: Reactive oxygen species (ROS) are considered fundamental in various physiological/pathophysiological processes and prevention/treatment measures such as hyperbaric oxygen (HBO) therapy. In this study, the origination of ROS in human umbilical vein endothelial cells was investigated under basal and HBO conditions. Methods: Whole cell or mitochondria-targeted fluorescent probes were applied to mark superoxide anion $\left(\mathrm{O}_{2}{ }^{-}\right)$, and the ROS produced from mitochondrial respiratory chain (MRC), NADPH oxidase (NOX) and xanthine oxidase (XO) were identified by flow cytometry, confocal imaging and microplate fluorometry with or without specific inhibitors. An algorithm was established to calculate ROS proportion of each source. Results: HBO increased ROS to about 2.14-2.44 fold in mitochondria and 1.32-1.42 fold in whole cell. Then ROS levels were significantly decreased by MRC inhibition about $30 \%$ and $16 \%$, respectively. NOX or XO inhibition did not affect HBO-induced ROS generation. Based on these data, it could be further estimated that mitochondrial ROS accounted for 32\%-39\% of basal whole-cell ROS including 3\% from MRC complex II, and NOX accounted for at least 24\%-29\%. Following HBO treatment, almost all increased ROS originated from mitochondria, and MRC complex II contributed at least $45 \%-60 \%$. Conclusion: This study provided a simple but effective method to estimate the origination of intracellular ROS and found that MRC were the main source of HBO-induced ROS generation.
\end{abstract}




\section{Cellular Physiology Cell Physiol Biochem 2018;47:1800-1808 \begin{tabular}{l|l} 
DOI: 10.1159/000491061 & Ond Biochemistry 2018 The Author(s). Published by S. Karger AG, Basel \\
wuww.karger.com/cpb
\end{tabular} \\ Zhou et al.: A Novel Approach to Estimate ROS Origination}

\section{Introduction}

Historically, reactive oxygen species (ROS) were viewed as purely harmful due to their potential to cause damage to lipids, proteins, and DNA [1], but sufficient evidence proved they are essential participants in cell signaling and regulation $[2,3]$. For instance, in endothelial cells ROS are the main cause of many vascular pathologies, such as diabetic and hyperpietic endothelial dysfunction, on the other hand, angiogenesis and endotheliumdependent vasorelaxation are under tight redox control [4-6]. Owing to their active and short-lived character, ROS must be generated at the precise subcellular compartment close to the molecules modified in ROS-dependent cell signaling and regulation processes $[7,8]$.

Hyperbaric oxygen (HBO) therapy, the practice of administering pure oxygen to patients while exposed to increased ambient pressure, is an effective treatment for $\mathrm{CO}$ poisoning, gas gangrene, decompression sickness and other maladies [9]. Accumulating evidence indicates that increased ROS may be fundamental in HBO therapy, in addition to the effects of increasing oxygen supply to alleviate tissue hypoxia $[10,11]$. Although, excessive HBO exposure would cause a massive ROS accumulation and lead to oxygen toxicity [11]. Modest increase of intracellular ROS during routine $\mathrm{HBO}$ treatment can modulate signaling pathways and induce the expression of cytoprotective proteins, thus enhancing cellular tolerance of harmful stimuli [12]. For example, our previous study found that HBO pretreatment significantly protected primary cultured rat spinal cord neurons from oxygen glucose deprivation and oxidative stress injury by ROS-triggered up-regulation of heat shock protein $32[13,14]$.

Normally, ROS are by-products of cell metabolism, but they can be generated in response to growth factors, cytokines and shear stress [15]. The pathways participating in cellular ROS generation mainly involve mitochondrial respiratory chain (MRC) complexes, NADPH oxidase (NOX) family and xanthine oxidase (XO) $[16,17]$. However, effective methods to estimate ROS origination in different cellular compartments under different conditions including HBO exposure have not previously been described. Knowledge of ROS origination and subcompartmental location appear to be of major importance for a detailed understanding of ROS in cell physiology and pathophysiology [8].

Relying on recently developed redox probes, specific inhibitors and fluorescence detections, spatiotemporal observation of defined ROS in subcellular compartments is permitted $[8,18]$. Based on these advances, we attempted an approach to estimate the origination of ROS in human umbilical vein endothelial cells (HUVECs) with or without HBO exposure. The relative performance of flow cytometer, confocal microscopy and microplate reader in detecting ROS were also compared.

\section{Materials and Methods}

\section{Cell culture}

The HUVECs (ATCC, USA) were grown in $25 \mathrm{~cm}^{2}$ culture flasks in Dulbecco's modified eagle medium (Invitrogen, USA) supplemented with 10\% fetal bovine serum (Gibico, USA). Cells were plated onto confocal dishes, 48-well plates or 6 -well plates 1 day before the test at a density of $1 \times 10^{5}$ cells $/ \mathrm{ml}$.

\section{HBO exposure}

HBO exposure was conducted in a temperature and humidity controlled hyperbaric cell incubator (OxyCure 3000, OxyHeal Health Group, USA). Cells were exposed to HBO for 60 min at $280 \mathrm{kPa}$, compression and decompression were both carried out in $5 \mathrm{~min}$. This protocol has previously been used in cell studies $[13,14]$. The chamber was flushed and compressed with oxygen containing $1.79 \% \mathrm{CO}_{2}$ to achieve a $5 \mathrm{kPa}$ partial pressure of $\mathrm{CO}_{2}$ to maintain a physiological $\mathrm{pH}$ range in medium. All pressures described in text are absolute. 


\section{Cellular Physiology Cell Physiol Biochem 2018:47:1800-1808 \begin{tabular}{c|l} 
and Biochemistry Published online: June 28, 2018 & $\begin{array}{l}\text { C } 2018 \text { The Author(s). Published by S. Karger AG, Basel } \\
\text { www.karger.com/cpb }\end{array}$ \\
\hline
\end{tabular}

\section{Fluorescence measurement}

Before HBO exposure, dihydroethidium (DHE, Thermo-fisher, USA), an agent which can be oxidized by superoxide anion $\left(\mathrm{O}_{2}^{-}\right)$and exhibit red fluorescence, was used to measure $\mathrm{O}_{2}^{-}$in whole-cell [19]. Mitochondrial $\mathrm{O}_{2}{ }^{-}$was measured by Mito-SOX (Thermo-fisher, USA) which can specifically target mitochondria. Cells were incubated in HBSS containing $5 \mu \mathrm{M}$ DHE or $5 \mu \mathrm{M}$ Mito-SOX for $20 \mathrm{~min}$ and washed with PBS twice. Then, cells were treated by phenol red-free DMEM with or without MRC complex II inhibitor thenoyltrifluoroacetone (TTFA, Sigma, USA), NOX 1/4 inhibitor GKT 137831 (GKT, Selleck, USA) or XO inhibitor Allopurinol (ALL, Selleck, USA), and delivered for HBO treatment. Immediately following HBO exposure, inverted confocal microscope (SP8, Leica, Germany), microplate reader (Hybrid reader Synergy H1, BioTek, USA) and flow cytometer (Cytoflex, Beckman Coulter, USA) were applied to acquire fluorescence signals.

\section{ROS origin estimating}

To simplify the estimation of ROS origin, inhibitors and fluorescence probes were considered to faithfully act on their intended sites. The proportions of NOX-source or XO-source ROS could be directly estimated from the respectively inhibited component in whole-cell fluorescence. For mitochondrial ROS estimation, cellular ROS could be divided and designated as follows: the basal whole-cell ROS (W) is sum of basal mitochondrial (M) and extra-mitochondrial ROS (EM); M is sum of basal part of mitochondrial ROS inhibited $\left(\mathrm{M}_{1}\right)$ and not inhibited $\left(\mathrm{M}_{2}\right)$ by TTFA; the HBO-induced ROS could be derived from extramitochondrial (em) and mitochondrial ROS, and the latter could be further divided into ROS inhibited $\left(\mathrm{m}_{1}\right)$ and not inhibited $\left(\mathrm{m}_{2}\right)$ by TTFA. The sources of the determined ROS in each group could be presented as follows:

ROS labeled by DHE in whole cell under air:

$\mathrm{DHE}_{\text {Air }}=\mathrm{W}=\mathrm{M}_{1}+\mathrm{M}_{2}+\mathrm{EM}$

ROS labeled by DHE in whole cell under HBO:

$\mathrm{DHE}_{\text {нво }}=\mathrm{M}_{1}+\mathrm{M}_{2}+\mathrm{EM}+\mathrm{m}_{1}+\mathrm{m}_{2}+\mathrm{em}$

The uninhibited part of DHE $_{\text {Air }}$ by TTFA:

$\mathrm{DHE}_{\text {Air }+\mathrm{TTFA}}=\mathrm{M}_{2}+\mathrm{EM}$

The uninhibited part of DHE $_{\text {нво }}$ by TTFA:

$\mathrm{DHE}_{\mathrm{HBO}+\mathrm{TTFA}}=\mathrm{M}_{2}+\mathrm{EM}+\mathrm{m}_{2}+\mathrm{em}$

Mitochondrial ROS labeled by Mito-SOX in whole cell under air:

Mito $_{\text {Air }}=\mathrm{M}=\mathrm{M}_{1}+\mathrm{M}_{2}$

Mitochondrial ROS labeled by Mito-SOX in whole cell under HBO:

Mito $_{\text {Hво }}=\mathrm{M}_{1}+\mathrm{M}_{2}+\mathrm{m}_{1}+\mathrm{m}_{2}$

The uninhibited part of Mito ${ }_{\text {Air }}$ by TTFA:

Mito $_{\text {Air+TTFA }}=\mathrm{M}_{2}$

The uninhibited part of Mito $_{\text {нво }}$ by TTFA:

Mito $_{\text {HBO+TTFA }}=\mathrm{M}_{2}+\mathrm{m}_{2}$

Because the inhibited part of ROS by TTFA in whole cell was theoretically all from mitochondria, we derive the equation:

$\mathrm{DHE}_{\text {нво }}-\mathrm{DHE}_{\mathrm{HBO}+\mathrm{TTFA}}=\mathrm{Mito}_{\mathrm{HBO}}-\mathrm{Mito}_{\mathrm{HBO}+\mathrm{TTFA}}$

There was no comparability between fluorescence values from DHE and Mito-SOX probes, since the relative values were adopted by comparing with respective basal value (air group). Thus, Equation (9) should be modified as:

$\mathrm{W} \times\left(\mathrm{DHE}_{\mathrm{HBO}}-\mathrm{DHE}_{\mathrm{HBO}+\mathrm{TTFA}}\right)=\mathrm{M} \times\left(\mathrm{Mito}_{\mathrm{HBO}}-\mathrm{Mito}_{\mathrm{HBO}+\mathrm{TTFA}}\right)$

From Equation (10), a conversion fraction between DHE and Mito-SOX values could be calculated:

$\mathrm{M} / \mathrm{W}=\left(\mathrm{DHE}_{\mathrm{HBO}}-\mathrm{DHE}_{\mathrm{HBO}+\mathrm{TTFA}}\right) /\left(\mathrm{Mito}_{\mathrm{HBO}}-\mathrm{Mito}_{\mathrm{HBO}+\mathrm{TTFA}}\right)$

Thereafter, proportions of ROS from different parts could be estimated as follows:

(1) Basal MRC complex II-source ROS:

$\mathrm{M}_{1} /\left(\mathrm{M}_{1}+\mathrm{M}_{2}+\mathrm{EM}\right)=\left[\left(\mathrm{Mito}_{\text {Air }}-\mathrm{Mito}_{\text {Air }+\mathrm{TTFA}}\right) \times \mathrm{M} / \mathrm{W}\right] / \mathrm{DHE}_{\text {Air }}$

(2) HBO induced MRC complex II-source ROS:

$\mathrm{m}_{1} /\left(\mathrm{m}_{1}+\mathrm{m}_{2}+\mathrm{em}\right)=$

$\left[\left(\mathrm{Mito}_{\mathrm{HBO}}-\mathrm{Mito}_{\mathrm{HBO}+\mathrm{TTFA}}-\mathrm{Mito}_{\text {Air }}+\mathrm{Mito}_{\mathrm{Air}+\mathrm{TTFA}}\right) \times \mathrm{M} / \mathrm{W}\right] /\left(\mathrm{DHE}_{\mathrm{HBO}}-\mathrm{DHE}_{\mathrm{Air}}\right)$

(3) HBO induced mitochondrial ROS: 


$$
\begin{aligned}
& \left(\mathrm{m}_{1}+\mathrm{m}_{2}\right) /\left(\mathrm{m}_{1}+\mathrm{m}_{2}+\mathrm{em}\right)= \\
& {\left[\left(\text { Mito }_{\mathrm{HBO}}-\mathrm{Mito}_{\text {Air }}\right) \times \mathrm{M} / \mathrm{W}\right] /\left(\mathrm{DHE}_{\mathrm{HBO}}-\mathrm{DHE}_{\text {Air }}\right)}
\end{aligned}
$$

Statistical analysis

The results are presented as mean \pm SD. Statistical analysis was performed with SPSS software (Version 18, IBM) using one-way ANOVA followed by Fisher's LSD and two way ANOVA of factorial design. $P<0.05$ was considered significant.

\section{Results}

$\mathrm{HBO}$ increased intracellular $\mathrm{O}_{2}^{-}$which was suppressed by MRC inhibitor TTFA

As shown in Fig. 1, HBO significantly increased mitochondrial and intracellular $\mathrm{O}_{2}^{-}$levels $(P<0.01)$, which could be inhibited by MRC complex II inhibitor TTFA $(P<0.01)$. No effect of TTFA on basal $\mathrm{O}_{2}^{-}$level was found $(P>0.05)$. HBO and TTFA interacted in the generation of $\mathrm{O}_{2}^{-}(P<0.05)$.

\section{Neither NOX nor $\mathrm{XO}$ changed $\mathrm{O}_{2}^{-}$production induced by $\mathrm{HBO}$}

NOX inhibitor GKT significantly decreased whole cell basal $\mathrm{O}_{2}^{-}(P<0.01$, Fig. 2$)$, but had no effect on mitochondrial basal $\mathrm{O}_{2}^{-}$and HBO-induced $\mathrm{O}_{2}^{-}$production $(P>0.05$, Fig. 2). XO inhibitor ALL had no impact on mitochondrial or whole cell $\mathrm{O}_{2}{ }^{-}$treated with $\mathrm{HBO}$ or air $(P>$ 0.05, Fig. 3). Neither GKT nor ALL interacted with HBO.

\section{The proportions of different sources ROS}

The proportions of different sources ROS in HUVECs under basal status or following HBO exposure are presented in Table 1.

\section{Discussion}

Endothelial cells, barrier between tissues and blood, are sensitive to oxygen partial pressure changes in blood [20]. Studies have shown that increasing oxygen partial pressure will enhance endothelial ROS generation and induce a variety of growth factors exerting

Fig. 1. Effects of MRC inhibitor TTFA on HBO induced $\mathrm{O}_{2}^{-}$generation. HUVECs were loaded with Mito-SOX $(5 \mu \mathrm{M})$ or DHE $(5 \mu \mathrm{M})$ for 20 min before HBO exposure with or without TTFA $(0.5 \mu \mathrm{M})$. The fluorescence intensity was detected immediately after HBO exposure by confocal microscope (representative images A-H under $63 \times$ oil lens, and histogram I), microplate reader (J) and flow cytometer $(\mathrm{K}) .{ }^{* *} \mathrm{P}<0.01$, compared with air group. ${ }^{\#}$ $\mathrm{P}<0.01,{ }^{\#} \mathrm{P}<0.05$, compared with HBO group. There is no comparability between the relative levels of DHE and Mito-SOX groups. HBO, hyperbaric oxygen; DHE, dhydroethidium; TTFA, thenoyltrifluoroacetone.

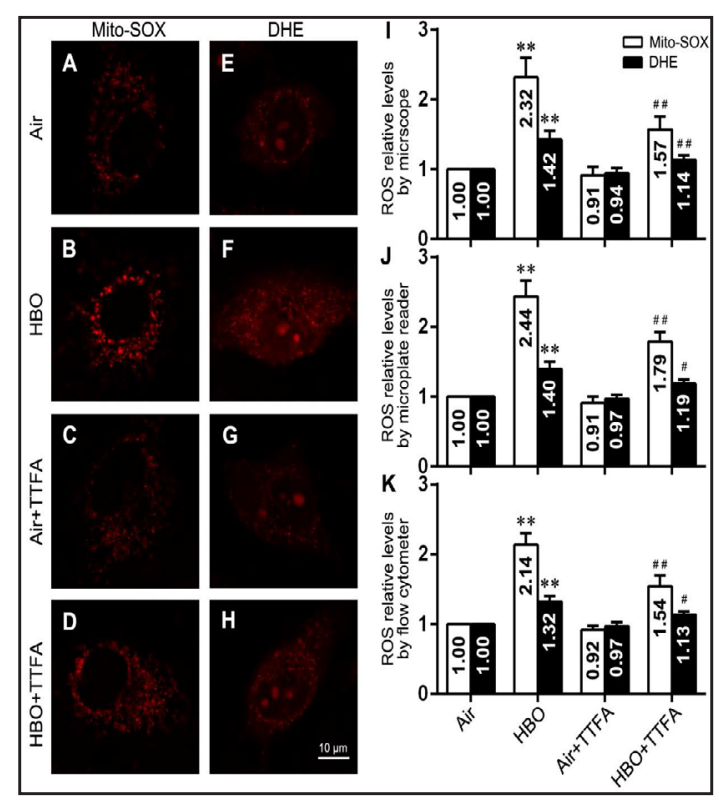


Fig. 2. Effects of NOX $1 / 4$ inhibitor GKT on HBO induced $\mathrm{O}_{2}^{-}$generation. GKT $(20 \mu \mathrm{M})$ was applied in HUVECs for $24 \mathrm{~h}$ before HBO exposure. The fluorescence intensity was detected immediately after HBO exposure by confocal microscope (representative images A-H under 63× oil lens, and histogram I), microplate reader (J) and flow cytometer (K). ${ }^{* *} \mathrm{P}<0.01$, compared with air group. There is no comparability between the relative levels of DHE and Mito-SOX groups. GKT, GKT 137831.

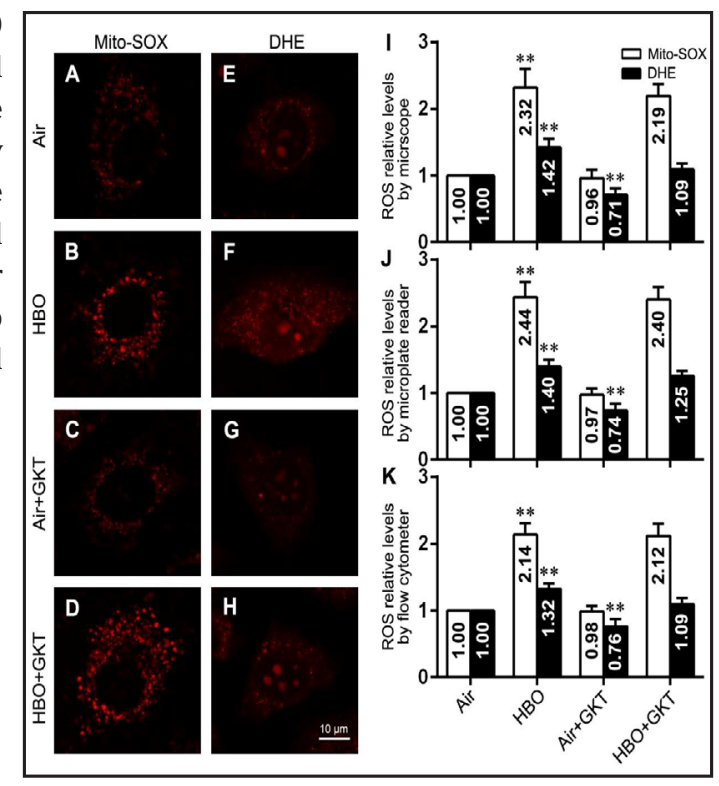

Fig. 3. Effects of XO inhibitor ALL on HBO induced $\mathrm{O}_{2}^{-}$generation. ALL $(3 \mu \mathrm{M})$ was applied in HUVECs before HBO exposure. The fluorescence intensity was detected immediately after HBO exposure by confocal microscope (representative images A-H under $63 \times$ oil lens, and histogram I), microplate reader (J) and flow cytometer $(\mathrm{K}){ }^{* *} \mathrm{P}<0.01$, compared with air group. There is no comparability between the relative levels of DHE and Mito-SOX groups. ALL, allopurinol.

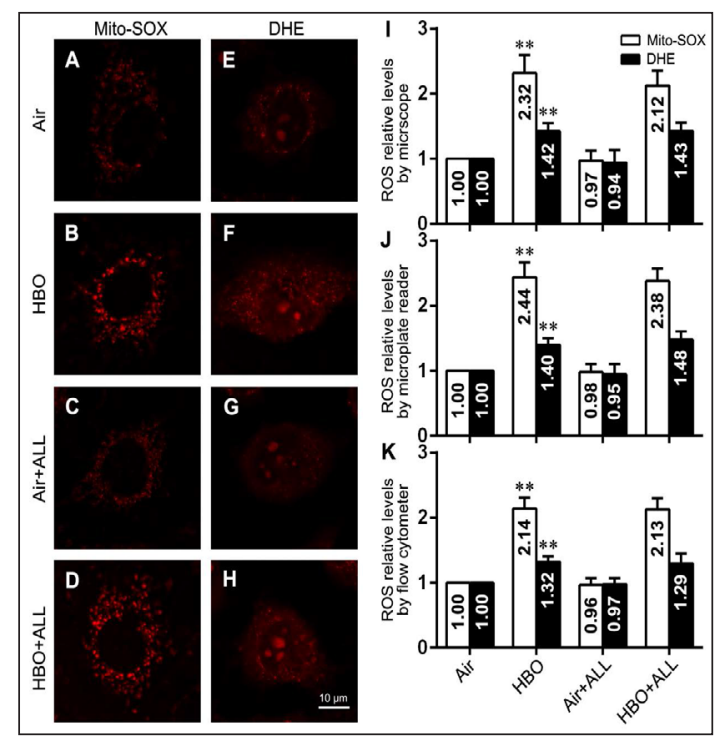

Table 1. The origination of ROS under basal status and following HBO exposure. ROS levels under basal and following HBO exposure were detected in HUVECs by confocal microscopy, microplate fluorometry and flow cytometry, and the proportions from different sources were calculated using the methodology described in ROS origin estimating. Notes: (a) The ROS proportions from mitochondria include that from MRCII. (b) HBO-induced ROS does not include the basal ROS. (c) Due to the efficiencies of inhibitors, the proportions of inhibited ROS should be higher than those calculated for basal MRCII, NOX and XO originated ROS. (d) As shown in Fig. 2 and 3, these values are all statistical non-significant. MRCII, mitochondrial respiratory chain complex II; NOX, NADPH oxidase; XO, xanthine oxidase

\begin{tabular}{lcccccccc}
\hline \multirow{2}{*}{ Methods } & \multicolumn{3}{c}{ Basal whole-cell ROS (\%) } & \multicolumn{4}{c}{ HBO-induced ROS (\%) } \\
& MRCII c,d & $\begin{array}{c}\text { Mito- } \\
\text { chondria }\end{array}$ & NOX $^{\mathrm{c}}$ & $\begin{array}{c}\text { XO } \\
\mathrm{c}, \mathrm{d}\end{array}$ & MRCII c $^{\mathrm{c}}$ & $\begin{array}{c}\text { Mito- } \\
\text { chondria }^{\mathrm{a}}\end{array}$ & NOX $^{\mathrm{c}, \mathrm{d}}$ & XO $^{\mathrm{c}, \mathrm{d}}$ \\
\hline Confocal microscopy & $>3$ & 39 & $>29$ & $>6$ & $>60$ & 120 & $>4$ & $>-6$ \\
Microplate fluorometry & $>3$ & 32 & $>26$ & $>5$ & $>45$ & 117 & $>-1$ & $>-14$ \\
Flow cytometry & $>3$ & 32 & $>24$ & $>3$ & $>50$ & 111 & $>-1$ & $>0$ \\
\hline
\end{tabular}




\section{Cellular Physiology Cell Physiol Biochem 2018;47:1800-1808 \\ \begin{tabular}{l|l} 
DOI: 10.1159/000491061 & and Biochemistry 2018 The Author(s). Published by S. Karger AG, Basel \\
wublished online: June 28, 2018 &
\end{tabular} \\ Zhou et al.: A Novel Approach to Estimate ROS Origination}

cytoprotective effects [21]. Hence, in this study, a widely used endothelial cell line HUVECs was adopted to explore ROS origination. A number of pathways participate in cellular ROS generation, among which MRC complexes, NOX family and XO are major sources $[16,17]$. The common product of these pathways is $\mathrm{O}_{2}^{-}$which is the precursor of ROS and can be converted to other types including hydrogen peroxide $\left(\mathrm{H}_{2} \mathrm{O}_{2}\right)$, hydroxyl radical $(\mathrm{HO} \bullet)$ and peroxynitrite $\left(\mathrm{ONOO}^{-}\right)$, etc [22]. Hence $\mathrm{O}_{2}^{-}$was detected using the whole-cell $\mathrm{O}_{2}^{-}$probe DHE and the mitochondria targeted $\mathrm{O}_{2}{ }^{-}$probe Mito-SOX, to represent total ROS levels under different conditions [23].

The main devices for fluorescence detection are flow cytometer, confocal microscopy and microplate reader, with respective advantages and disadvantages [24]. Flow cytometry is the most popular and sensitive method currently, but necessary steps such as digestion may influence ROS detection. Confocal microscopy can be used to acquire subcellular spacetime information, while the overlong time exposure may afford probe auto-oxidation or quenching, leading to deviation. Microplate reader detection is the most efficient way for multiple-sample detection, but as it is unable to measure individual cell fluorescence, its general accuracy is thought to be inferior to the others. To ensure the reliability of estimation and compare methods, all three techniques were adopted in this study and the results were in keeping with the aforementioned aspects. Nonetheless, the main findings were consistent across all three methods. From the confocal images, it can be seen that nuclei and/or mitochondria were labeled by DHE or Mito-SOX. However, due to the probes' DNA affinity and required higher resolution, precise ROS locations cannot be identified correctly in images [24]. Flow cytometry values had the least variation between repetitions among the three methods.

In MRC, electrons transport through complexes then react with oxygen and protons, converting to water. During this process, electrons may escape and oxidize oxygen to produce $\mathrm{O}_{2}{ }^{-}[25,26]$. MRC complex I and III have been demonstrated as the main sites of mitochondrial $\mathrm{O}_{2}^{-}$generation [26]. However, instead of inhibiting ROS generation, existing complex I and III inhibitors like rotenone and antimycin A exert opposite effects [27, 28]. These inhibitors break up electron transport and cause upstream electron carriers to become fully reduced, leading to more electron leakage [27]. TTFA, a MRC complex II inhibitor, is well known to suppress mitochondrial ROS generation $[29,30]$. This may due to the inhibition of succinateubiquinone reductase which can produce $\mathrm{O}_{2}{ }^{-}$via reversely transporting electrons to complex I [30]. In a pathway differs from MRC complexes, NOX can transfer electrons from NADPH to oxygen, and form $\mathrm{O}_{2}{ }^{-}$enzymatically [31]. NOX was firstly identified in phagocytic plasma membrane, then other isoforms were subsequently found in a variety of non-phagocytic cells to provide basal ROS [31]. There are 7 homologues in the NOX family and NOX4 is the predominant NOX in endothelial cells [32]. GKT is a specific inhibitor of NOX $1 / 4$ and was used in this study to investigate the role of NOX in HUVECs ROS generation. XO utilizes oxygen as an electron acceptor generates $\mathrm{O}_{2}{ }^{-}$during purine metabolism, and purine analog ALL can competitively inhibit purine metabolism and reduce $\mathrm{O}_{2}{ }^{-}$formation [33].

Taking advantage of aforementioned ROS fluorescent probes, detection methods, specific inhibitors and HBO induction, an approach to estimate ROS origination was established in this study. The approach enabled identifying not only the sources of increased ROS by stimulants such as HBO, but also the origin of basal intracellular ROS. The critical role of HBO was to work as an amplifier of ROS generation, which would mitigate much possible inaccuracy in the determination of tiny ROS levels under basal conditions, especially the component from MRC complex II. This was the reason why the M/W ratio described in ROS origin estimating was calculated by respective HBO values instead of air values. Without the data from HBO treatment, it would be impossible to calculate the basal levels of mitochondrial ROS. Of course, other ROS inducers may also work with this methodology.

However, limited by imperfection of probes, inhibitors and detection methods, inaccuracy and deviation in the results are currently inevitable. For DHE and Mito-SOX, though widely used in more than $70 \%$ related studies, both will react with other ROS to form products that have overlapping fluorescence emission spectra [18, 34]. However, these 
aspects do not affect the estimation of the percentage of ROS origin by the methodology. Other potential confounding factors, such as mitochondrial ROS stimulate extra-mitochondrial ROS generation which could be indirectly inhibited by TTFA [35, 36], may lead to over estimating the percentages of HBO-induced mitochondrial ROS (higher than 100\%) shown in Table 1.

In spite of these deficiencies, the algorithm still provides an efficient method for estimating intracellular ROS origination. As listed in Table 1, under basal conditions, mitochondria accounted for 32\%-39\%, NOX and XO contributed at least $24 \%-29 \%$ and $3 \%-6 \%$ respectively. The results support previous reports that mitochondria and NOX are the major ROS sources under basal status in endothelial cells [37, 38]. MRC complex II contributed less than 10\% (3\%/(32\%-39\%)) of mitochondrial ROS, because it takes only a relatively small proportion of electrons along the MRC transport [16].

Following $1 \mathrm{~h}$ HBO exposure, endothelial ROS increased 32\%-42\%, all of which came from mitochondria and MRC complex II contributed 38\%-50\%. Although obvious variation exists, NOX and XO did not increase ROS generation under HBO according to the proportions in Table 1. Increasing oxygen partial pressures led mitochondrial hyperoxia not only provided sufficient oxygen substrate, but also stimulated cell respiration and enhanced electron transport in MRC, which led to increased electron leakage and ROS formation [39, 40]. In MRC complex II these effects might be further enhanced with electrons supplied by succinate and ubiquinone, led to more ROS generation [41].

In conclusion, this study established an approach to estimate the origination of intracellular ROS and found that MRC were the main source of HBO-induced ROS generation in endothelial cells. Knowledge of detailed intracellular ROS origination is pivotal in understanding of ROS triggered physiological and pathophysiological processes, whether the inducers are exogenous or endogenous [1]. This approach is also applicable to explore intracellular ROS induced by other clinical or experimental treatments which act via ROS induction. With the optimization of detection methods, specific inhibitors and redox probes, the approach will be more suitable and reliable for ROS research.

\section{Acknowledgements}

This work was supported by the National Natural Science Foundation of China, No. 81772014.

\section{Disclosure Statement}

The authors declare that there is no conflict of interests.

\section{References}

1 Alfadda AA, Sallam RM: Reactive oxygen species in health and disease. J Biomed Biotechnol 2012;2012:936486.

-2 Dan Dunn J, Alvarez LA, Zhang X, Soldati T: Reactive oxygen species and mitochondria: A nexus of cellular homeostasis. Redox Biol 2015;6:472-485.

-3 Ray PD, Huang BW, Tsuji Y: Reactive oxygen species (ros) homeostasis and redox regulation in cellular signaling. Cell Signal 2012;24:981-990.

-4 Craige SM, Kant S, Keaney JF, Jr.: Reactive oxygen species in endothelial function - from disease to adaptation. Circ J 2015;79:1145-1155.

-5 Deng Y, Han X, Yao Z, Sun Y, Yu J, Cai J, Ren G, Jiang G, Han F: Pparalpha agonist stimulated angiogenesis by improving endothelial precursor cell function via a nlrp3 inflammasome pathway. Cell Physiol Biochem 2017;42:2255-2266. 


\section{Cellular Physiology Cell Physiol Biochem 2018;47:1800-1808 \begin{tabular}{l|l} 
DOI: 10.1159/000491061 & and Biochemistry \\
Published online: June 28, 2018 & $\begin{array}{l}\text { 2018 The Author(s). Published by S. Karger AG, Basel } \\
\text { www.karger.com/cpb }\end{array}$
\end{tabular} \\ Zhou et al.: A Novel Approach to Estimate ROS Origination}

6 Ding XQ Ban T, Liu ZY, Lou J, Tang LL, Wang JX, Chu WF, Zhao D, Song BL, Zhang ZR: Transient receptor potential melastatin 4 (trpm4) contributes to high salt diet-mediated early-stage endothelial injury. Cell Physiol Biochem 2017;41:835-848.

7 Jones DP, Go YM: Redox compartmentalization and cellular stress. Diabetes Obes Metab 2010;12 Suppl 2:116-125.

8 Kaludercic N, Deshwal S, Di Lisa F: Reactive oxygen species and redox compartmentalization. Front Physiol 2014;5:285.

-9 Fife CE, Eckert KA, Carter MJ: An update on the appropriate role for hyperbaric oxygen: Indications and evidence. Plast Reconstr Surg 2016;138:107s-116s.

10 Thom SR: Oxidative stress is fundamental to hyperbaric oxygen therapy. J Appl Physiol (1985) 2009;106:988-995.

11 Poff AM, Kernagis D, D’Agostino DP: Hyperbaric environment: Oxygen and cellular damage versus protection. Compr Physiol 2016;7:213-234.

12 Hink J, Jansen E: Are superoxide and/or hydrogen peroxide responsible for some of the beneficial effects of hyperbaric oxygen therapy? Med Hypotheses 2001;57:764-769.

13 Huang G, Xu J, Xu L, Wang S, Li R, Liu K, Zheng J, Cai Z, Zhang K, Luo Y, Xu W: Hyperbaric oxygen preconditioning induces tolerance against oxidative injury and oxygen-glucose deprivation by upregulating heat shock protein 32 in rat spinal neurons. PLoS One 2014;9:e85967.

14 Huang G, Diao J, Yi H, Xu L, Xu J, Xu W: Signaling pathways involved in hsp32 induction by hyperbaric oxygen in rat spinal neurons. Redox Biol 2016;10:108-118.

15 Ushio-Fukai M: Compartmentalization of redox signaling through nadph oxidase-derived ros. Antioxid Redox Signal 2009;11:1289-1299.

-16 Turrens JF: Mitochondrial formation of reactive oxygen species. J Physiol 2003;552:335-344.

17 Brown GC, Borutaite V: There is no evidence that mitochondria are the main source of reactive oxygen species in mammalian cells. Mitochondrion 2012;12:1-4.

$\checkmark 18$ Dikalov SI, Harrison DG: Methods for detection of mitochondrial and cellular reactive oxygen species. Antioxid Redox Signal 2014;20:372-382.

-19 Kuznetsov AV, Kehrer I, Kozlov AV, Haller M, Redl H, Hermann M, Grimm M, Troppmair J: Mitochondrial ros production under cellular stress: Comparison of different detection methods. Anal Bioanal Chem 2011;400:2383-2390.

20 Ma X, Zhang H, Pan Q, Zhao Y, Chen J, Zhao B, Chen Y: Hypoxia/aglycemia-induced endothelial barrier dysfunction and tight junction protein downregulation can be ameliorated by citicoline. PLoS One 2013;8:e82604.

-21 Godman CA, Chheda KP, Hightower LE, Perdrizet G, Shin DG, Giardina C: Hyperbaric oxygen induces a cytoprotective and angiogenic response in human microvascular endothelial cells. Cell Stress Chaperones 2010;15:431-442.

-22 Winterbourn CC: Reconciling the chemistry and biology of reactive oxygen species. Nat Chem Biol 2008;4:278-286.

23 Ribou AC: Synthetic sensors for reactive oxygen species detection and quantification: A critical review of current methods. Antioxid Redox Signal 2016;25:520-533.

-24 Griendling KK, Touyz RM, Zweier JL, Dikalov S, Chilian W, Chen YR, Harrison DG, Bhatnagar A: Measurement of reactive oxygen species, reactive nitrogen species, and redox-dependent signaling in the cardiovascular system: A scientific statement from the american heart association. Circ Res 2016;119:e3975.

25 Tahara EB, Navarete FD, Kowaltowski AJ: Tissue-, substrate-, and site-specific characteristics of mitochondrial reactive oxygen species generation. Free Radic Biol Med 2009;46:1283-1297.

26 Brand MD: The sites and topology of mitochondrial superoxide production. Exp Gerontol 2010;45:466-472.

27 Drose S, Hanley PJ, Brandt U: Ambivalent effects of diazoxide on mitochondrial ros production at respiratory chain complexes i and iii. Biochim Biophys Acta 2009;1790:558-565.

28 Zhou Q Liu C, Liu W, Zhang H, Zhang R, Liu J, Zhang J, Xu C, Liu L, Huang S, Chen L: Rotenone induction of hydrogen peroxide inhibits mtor-mediated s6k1 and 4e-bp1/eif4e pathways, leading to neuronal apoptosis. Toxicol Sci 2015;143:81-96. 


\section{Cellular Physiology Cell Physiol Biochem 2018;47:1800-1808 \begin{tabular}{l|l} 
DOI: 10.1159/000491061 & $\begin{array}{l}\text { O 2018 The Author(s). Published by S. Karger AG, Basel } \\
\text { www.karger.com/cpb }\end{array}$
\end{tabular} \\ Zhou et al.: A Novel Approach to Estimate ROS Origination}

-29 Emerling BM, Platanias LC, Black E, Nebreda AR, Davis RJ, Chandel NS: Mitochondrial reactive oxygen species activation of p38 mitogen-activated protein kinase is required for hypoxia signaling. Mol Cell Biol 2005;25:4853-4862.

-30 Moreno-Sanchez R, Hernandez-Esquivel L, Rivero-Segura NA, Marin-Hernandez A, Neuzil J, Ralph SJ, Rodriguez-Enriquez S: Reactive oxygen species are generated by the respiratory complex ii--evidence for lack of contribution of the reverse electron flow in complex i. Febs j 2013;280:927-938.

-31 Bedard K, Krause KH: The nox family of ros-generating nadph oxidases: Physiology and pathophysiology. Physiol Rev 2007;87:245-313.

-32 Ago T, Kitazono T, Ooboshi H, Iyama T, Han YH, Takada J, Wakisaka M, Ibayashi S, Utsumi H, Iida M: Nox4 as the major catalytic component of an endothelial nad(p)h oxidase. Circulation 2004;109:227-233.

33 Kang SM, Lim S, Song H, Chang W, Lee S, Bae SM, Chung JH, Lee H, Kim HG, Yoon DH, Kim TW, Jang Y, Sung JM, Chung NS, Hwang KC: Allopurinol modulates reactive oxygen species generation and ca2+ overload in ischemia-reperfused heart and hypoxia-reoxygenated cardiomyocytes. Eur J Pharmacol 2006;535:212-219.

-34 Yang K, Kolanowski JL, New EJ: Mitochondrially targeted fluorescent redox sensors. Interface Focus 2017;7:20160105.

35 Daiber A, Di Lisa F, Oelze M, Kroller-Schon S, Steven S, Schulz E, Munzel T: Crosstalk of mitochondria with nadph oxidase via reactive oxygen and nitrogen species signalling and its role for vascular function. $\mathrm{Br} \mathrm{J}$ Pharmacol 2017;174:1670-1689.

-36 Zorov DB, Juhaszova M, Sollott SJ: Mitochondrial reactive oxygen species (ros) and ros-induced ros release. Physiol Rev 2014;94:909-950.

37 Sedeek M, Hebert RL, Kennedy CR, Burns KD, Touyz RM: Molecular mechanisms of hypertension: Role of nox family nadph oxidases. Curr Opin Nephrol Hypertens 2009;18:122-127.

-38 Panieri E, Santoro MM: Ros signaling and redox biology in endothelial cells. Cell Mol Life Sci 2015;72:32813303.

39 Boveris A, Costa LE, Cadenas E, Poderoso JJ: Regulation of mitochondrial respiration by adenosine diphosphate, oxygen, and nitric oxide. Methods Enzymol 1999;301:188-198.

40 Drose S, Brandt U: Molecular mechanisms of superoxide production by the mitochondrial respiratory chain. Adv Exp Med Biol 2012;748:145-169.

41 Quinlan CL, Orr AL, Perevoshchikova IV, Treberg JR, Ackrell BA, Brand MD: Mitochondrial complex ii can generate reactive oxygen species at high rates in both the forward and reverse reactions. J Biol Chem 2012;287:27255-27264. 